\title{
Growth and Characterization of Co-Doped L-Lysine Monohydrochloride Dihydrate (CLMHCl) Single Crystals by Slow Evaporation Method
}

\author{
V. RAJENDRAN* and S. GNANAM \\ Department of Physics, Presidency College, \\ Chennai-600 005, Tamilnadu, India \\ gnanam.physics@gmail.com
}

Received 7 July 2011; Accepted 20 September 2011

\begin{abstract}
Single crystal of Cobalt doped L-Lysine monohydrochloride dihyrate (CLMHCl) was grown by slow evaporation technique from its aqueous solution. The effects of Co-doping on the growth, structural, and optical properties of CLMHCl crystal have been investigated. To grow good quality crystals $\mathrm{pH}$ value of growth solution has been optimized and solubility of $\mathrm{CLMHCl}$ values was determined. The cell parameters are verified by single crystal X-ray Diffraction. Fourier transform infrared spectum (FT-IR) is used to confirm the presence of various functional groups in the grown crystal. The presence of Co in the grown crystal was confirmed by Inductively-coupled plasma (ICP) elemental analysis. The optical transmission study shows that the $\mathrm{CLMHCl}$ crystal has good optical transparency in the UV and visible regions.
\end{abstract}

Keywords: Semiorganic crystal, CLMHCl, Slow evaporation method, Optical properties.

\section{Introduction}

Non linear optical materials find extensive optoelectronic applications such as optical frequency conversion, optical communication, optical data storage and optical switches ${ }^{1-3}$. The organic NLO materials have large nonlinear optical coefficients compared to inorganic material, but their use is impended by their poor mechanical and thermal properties, low laser damage threshold ${ }^{4}$. The pure inorganic materials have excellent mechanical and thermal properties but possess relatively modest optical nonlinearities due to lack of extended $\pi$-electron delocalization ${ }^{5}$. In view of these problems, new types of hybrid NLO material have been explored from organic and inorganic complexes called semi organic ${ }^{6}$. In these materials high optical nonlinearity of purely organic compound is combined with the favorable mechanical and thermal properties of inorganic materials ${ }^{7,8}$. Several dopants can affect the structural and physical properties of the host compound ${ }^{9,10}$.

We can dope various dopants to enhance the nonlinear properties of host compounds. In present investigation transition metal dopant $\mathrm{Co}^{2+}$ was added in molar percent in saturated 
$\mathrm{LMHCl}$ solution to enhance nonlinear properties of $\mathrm{LMHCl}$. The nonlinear optical properties of LMHCl crystals were reported elsewhere ${ }^{11}$.

In this present work, we report the single crystal growth of $\mathrm{Co}^{2+}$ doped L-Lysine monohydrochloride dihydrate $(\mathrm{CLMHCl})$ followed by characterization of the grown crystals by single crystal X-ray diffraction, solubility test, FTIR spectroscopy, ICP elemental analysis and optical transparency measurements.

\section{Experimental}

Single crystals of CLMHCl was grown by dissolving (AR grade) stoichiometric amount of L-Lysine monohydrochloride dihydrate in $100 \mathrm{ml}$ distilled water and then followed by $2 \mathrm{~mol} \%$ of cobalt acetate was added to the above transparent solution under magnetic stirring $(\mathrm{pH}=2)$. The saturated solution was filtered and allowed to evaporate at room temperature. After seed crystals growing period, the pink color of the solution is changed into violet colored solution. Good quality of crystals has been harvested in a span of 20 days. The crystals obtained from the slow evaporation method have maximum dimensions of $28 \times 20 \times 4 \mathrm{~mm}^{3}$. The grown crystal is shown in Figure 1 .

\section{Characterization}

Single crystal X-ray diffraction analysis of CLMHCl was recorded using Enraf Nonius CAD4 MV31 and Enraf Nonius CAD4F automatic X-ray diffractometer. The grown crystals were subjected to FT-IR analysis with sample prepared with $\mathrm{KBr}$ in the palletized form. The FT-IR spectrum of CLMHCl was recorded in the region 4000-400 $\mathrm{cm}^{-1}$ employing Bruker IFS $66 \mathrm{~W}$ Spectrometer. Inductively-coupled plasma (ICP) elemental analysis has become important tool for characterizing the metal elements present in the crystal. In present investigation the grown crystal was subjected to ICP analysis to confirm the presence of cobalt in grown crystal by ICP-OES-Perkin Elmer Optima 5300 DV. The optical property of the $\mathrm{CLMHCl}$ was assessed by using UV-vis absorption spectra using a Varian Cary $5 \mathrm{E}$ spectrophotometer in the range of 200-2000 nm.

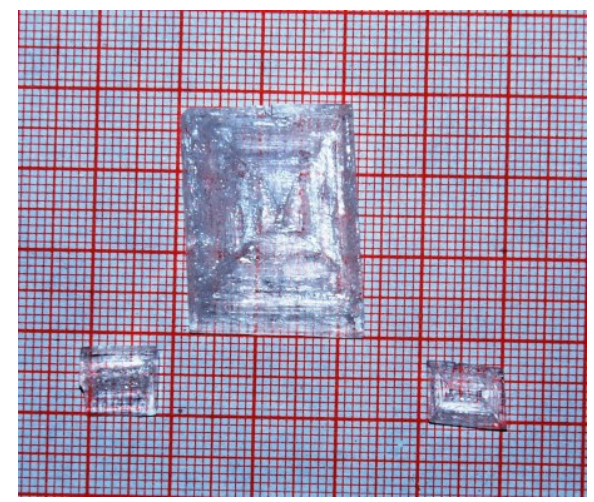

Figure 1. As grown CLMHCl crystal.

\section{Results and Discussion}

Single crystal $X$-ray diffraction analysis

A single crystal XRD revealed that the cell parameters of $\mathrm{CLMHCl}$ as $\mathrm{a}=5.87 \AA, \mathrm{b}=13$. $31 \AA, c=7.49 \AA, \alpha=90^{\circ}, \beta=97.77^{\circ}, \gamma=90^{\circ}$, Volume $=580 \AA^{3}$. The crystal system is monoclinic with space group $\mathrm{P} 2{ }_{1}$. The calculated lattice parameters for the pure $\mathrm{LMHCl}$ was found to be 
$\mathrm{a}=5.91 \AA, \mathrm{b}=13.39 \AA, \mathrm{c}=7.54 \AA^{11}$, and Volume $=592.23 \AA^{3}$. Thus, the XRD results confirm the incorporation of metal ions in the crystal lattice of $\mathrm{LMHCl}$ but do not change the crystal structure though there is a change in the lattice parameters. As previously, reported ${ }^{11}$ values are compared with the present investigations are listed in the Table 1.

Table 1. Cell parameters of pure and metal ions doped LMHCL single crystals.

\begin{tabular}{ccccc}
\hline Samples & $\mathrm{a}(\AA)$ & $\mathrm{b}(\AA)$ & $\mathrm{c}(\AA)$ & Volume $\left(\AA^{3}\right)$ \\
\hline Pure LMHCl & 5.91 & 13.39 & 7.54 & 592.23 \\
Co-LMHCl & 5.87 & 13.31 & 7.49 & 580 \\
\hline
\end{tabular}

\section{Solubility test}

Recrystallized salt was used for the solubility studies. Solubility of CLMHCl in water was determined by dissolving the solute in water taken in an airtight container maintained at a constant temperature with continuous stirring. After attaining saturation, the equilibrium concentration of the solute was analyzed gravimetrically. The solubility of the synthesized $\mathrm{CLMHCl}$ as a function of temperature for five different temperatures $30-50{ }^{\circ} \mathrm{C}$ in water were determined and plotted as shown in Figure 2. It was determined that the material possesses a positive gradient of solubility with a good solubility.

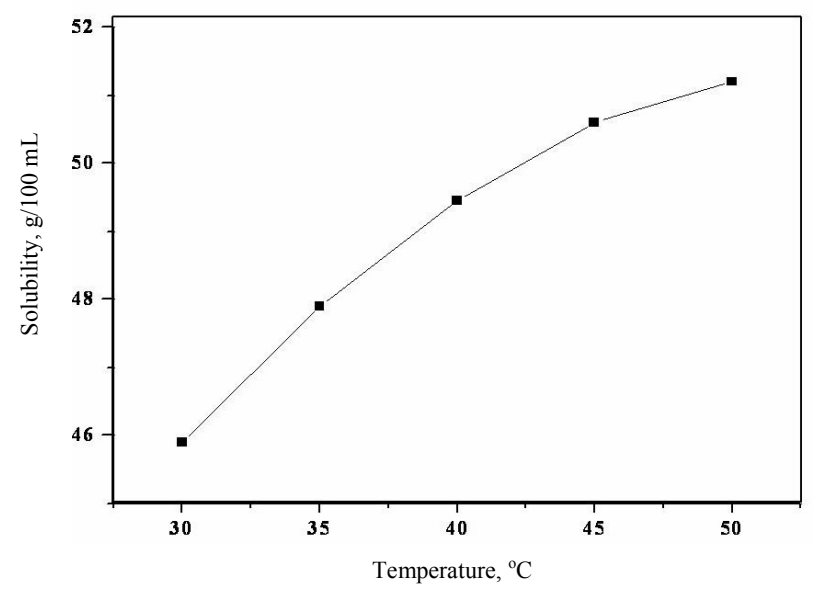

Figure 2. The solubility curve of CLMHCl single crystals.

\section{FTIR analysis}

Figure 3 shows the FTIR spectrum of CLMHCL crystal. The stretching frequency around $3456 \mathrm{~cm}^{-1}$ clearly indicates $\mathrm{O}-\mathrm{H}$ stretching of carboxylic acid group and the presence of hydrogen bonding and water molecule in the crystal lattice. Sharp peaks near $3169 \mathrm{~cm}^{-1}$ and $3029 \mathrm{~cm}^{-1}$ are due to symmetric stretching bands of $\mathrm{N}-\mathrm{H}$ and $\mathrm{C}-\mathrm{H}$ in the compound, respectively. The C-H stretching and bending is at 2614 and $1344 \mathrm{~cm}^{-1}$, respectively. In the spectrum, the bands near 1618 and $1401 \mathrm{~cm}^{-1}$ are due to the presence of the $\mathrm{COO}^{-}$ (Carboxylate ion) in the CLMHCl. The band near $2713 \mathrm{~cm}^{-1}$ and $2264 \mathrm{~cm}^{-1}$ may be assigned to a combination of the asymmetrical $\mathrm{NH}_{2}{ }^{+}$stretching vibrations and torsional oscillation of the $\mathrm{NH}_{3}{ }^{+}$group. The $\mathrm{NH}_{3}{ }^{+}$stretching region shows broad bands characteristics of hydrogen bonding. The peaks at $2965,1583,1506 \mathrm{~cm}^{-1}$ is due to the $\mathrm{NH}_{3}{ }^{+}$stretching vibrations. The 
C-C-N symmetric and asymmetric stretching is found to be at 868 and $1092 \mathrm{~cm}^{-1}$. The band appearing at $742 \mathrm{~cm}^{-1}$ infers the $\mathrm{C}-\mathrm{O}-\mathrm{H}$ stretching of the CLMHCL crystals. Thus, the existence of these small shifts is due to the presence of $\mathrm{Co}^{2+}$ ions present in the crystal structure of pure $\mathrm{LMHCl}^{11}$. The prominent peak at $545 \mathrm{~cm}^{-1}$ can be assigned to the stretching of metal ion; it confirms the presence of host material $\left(\mathrm{Co}^{2+}\right)$ in the crystal lattice. The frequency assignment for CLMHCL with various functional groups is presented in Table 2.

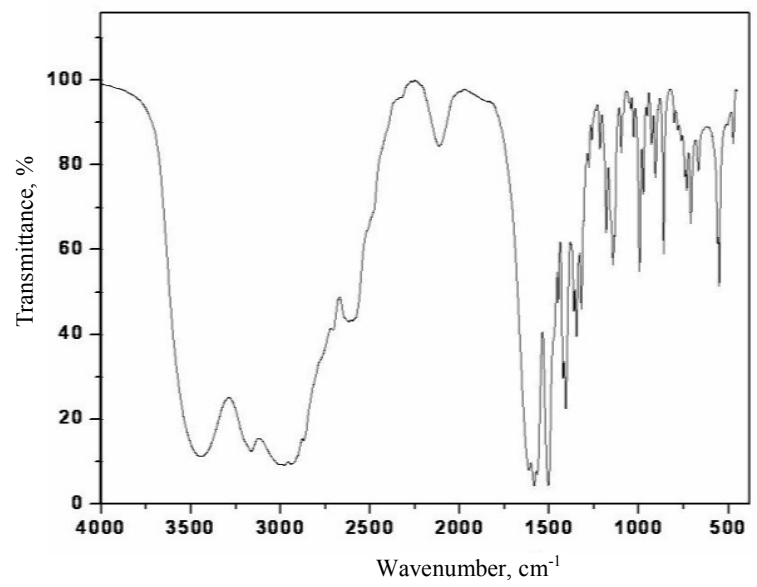

Figure 3. FTIR spectrum of CLMHCl crystal.

Table 2. FTIR spectral assignments for CLMHCl single crystal.

\begin{tabular}{cl}
\hline Wavenumber, $\mathrm{cm}^{-1}$ & \multicolumn{1}{c}{ Assignment } \\
\hline 3456 & $\mathrm{O}-\mathrm{H}$ stretch of water \\
3169 & $\mathrm{~N}-\mathrm{H}$ symmetric stretching \\
3029 & $\mathrm{C}-\mathrm{H}_{\text {symmetric stretching }}$ \\
2965 & $\mathrm{NH}_{3}^{+}$stretching \\
2713 & $\mathrm{NH}_{2}^{+}$asymmetric stretching \\
2614 & $\mathrm{C}-\mathrm{H}$ stretching \\
2264 & torsional oscillation of $\mathrm{NH}_{3}^{+}$ \\
1618 & ${\mathrm{Symmetric} \mathrm{mode} \mathrm{of} \mathrm{COO}^{-}}^{+}$ \\
1583 & $\mathrm{NH}_{3}^{+}$stretching \\
1506 & $\mathrm{NH}_{3}^{+}$stretching \\
1401 & $\mathrm{Symmetric} \mathrm{mode} \mathrm{of} \mathrm{COO}^{-}$and C-N \\
& stretching \\
1344 & $\mathrm{C}-\mathrm{H}$ bending \\
1092 & $\mathrm{C}-\mathrm{C}-\mathrm{N}$ asymmetric stretching \\
868 & $\mathrm{C}-\mathrm{C}-\mathrm{N}$ symmetric stretching \\
742 & $\mathrm{C}-\mathrm{O}-\mathrm{H}$ stretching \\
\hline
\end{tabular}

\section{ICP elemental analysis}

In order to determine the exact weight percentage of $\mathrm{Co}^{2+}$ present in CLMHCl crystals, $20 \mathrm{mg}$ of fine powder of the crystal was prepared and dissolved in $10 \mathrm{~mL}$ of triple distilled water. This prepared solution was subjected to ICP elemental analysis. From the analysis, 
the mean weight of cobalt present in the sample is $0.803 \mathrm{mg} / \mathrm{L}$. The cobalt weight $\%$ can be calculated from the equation,

$$
\mathrm{Wt} \%=\frac{\mathrm{ppm}(\mathrm{mg} / \mathrm{L}) \mathrm{X} \text { Volume in } \mathrm{mL} \times \text { dilution factor } \mathrm{X} 10^{-4}}{\text { Weight of samples in grams }}
$$

The results show that only $0.24 \%$ of $\mathrm{Co}^{2+}$ is present in the samples. It was observed that the amount of dopant incorporated into the crystal lattice is far below its original concentration in the solution.

\section{Optical transmittance studies}

The optical transmission spectrum of CLMHCl is shown in Figure 4. The cut off wavelength as observed from the transmission spectrum is found to be $231 \mathrm{~nm}$. CLMHCl has a wide transmission window between 200 and $1500 \mathrm{~nm}$ and hence, the material is suitable for generating second harmonics in the blue-green region. The presence of metal ions in the crystal lattice enhances the optical activity. The large transmission in the visible region enables it to be a potential candidate for optoelectronic applications ${ }^{12}$. There is an absorption line in the near infrared which may be caused by water molecule. From the high-energy edge of the transmission, when it is almost equal to zero, it turns out that the forbidden energy gap $\mathrm{Eg}$ of $\mathrm{CLMHCl}$ is $5.36 \mathrm{eV}$.

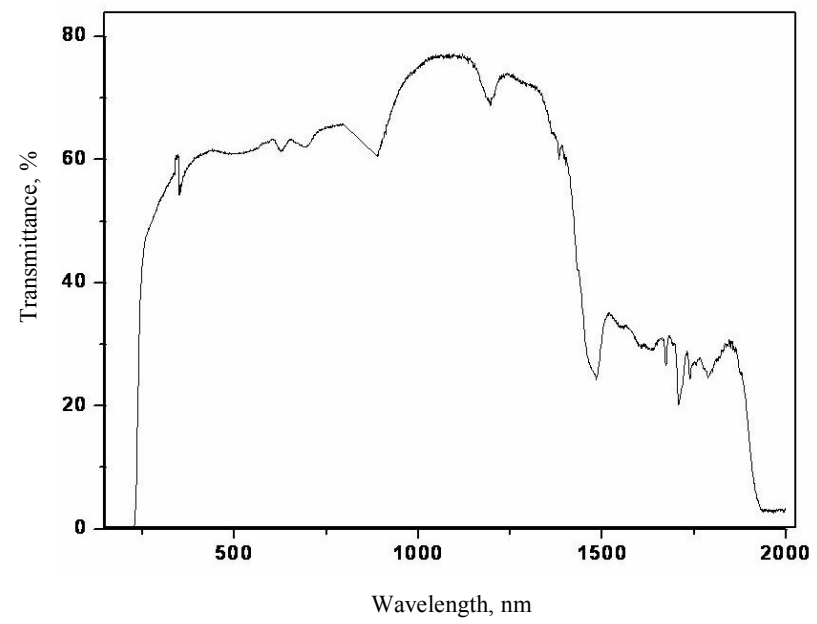

Figure 4. Optical transmission spectrum of CLMHCl.

\section{Conclusion}

The $2 \mathrm{~mol} \%$ cobalt doped $\mathrm{LMHCl}$ crystal was grown by low temperature solution growth, slow evaporation technique. Monoclinic structure of grown crystal was confirmed from single crystal X-ray diffraction analysis. The FTIR spectrum confirms the presence of functional groups. ICP elemental analysis confirms the presence of Cobalt in the grown crystal. UV-visible study reveals lower cutoff wavelength at around $231 \mathrm{~nm}$ and crystal has wide range of transparency in UV and visible regions. The presence of $\mathrm{Co}^{2+}$ modifies the structural and optical properties of the grown crystals. Thus, the grown crystal is a potential candidate for NLO applications. 


\section{Acknowledgment}

The authors are grateful to the University Grant Commission for extending financial support to carryout this work.

\section{References}

1. Liu W J, Ferrari C, Zha M, Zanotti L and Jiang S S, Cryst Res Technol., 2000, 35, 1215.

2. $\mathrm{Hu} \mathrm{Z}$ G, Ushiyama N, Yap Y K, Yoshimura M, Mori Y and Sasaki T, J Cryst Growth., 2002, 237, 654.

3. Dhanuskodi S and Vasantha K, Spectrochim Acta A, 2005, 61, 1777.

4. Min-hua Jiang and Qi Fang, Adv Mater., 1999, 11, 147.

5. Ramajothi J, Dhanuskodi S and Nagarajan K, Cryst Res Technol., 2004, 39, 414.

6. Ariponnammal S, Radhika S, Selva R and Victor Jeya N, Cryst Res Technol., 2005 40, 786.

7. Rosker M.J, Cunningham P, Ewbank M D, Marcy H O, Vachss F R, Warren L F, Gappinger R and Borwick R, Pure Appl Opt., 1996 5, 667.

8. Selvaraju K, Valluvan R, Kirubavathi K and Kumararaman S, Opt Commun., 2007 269, 230.

9. Ushasree P M, Jayavel R and Ramasamy P, Mater Sci Eng B, 1999, 65, 153.

10. Kannan V, Bairava Ganesh R, Sathyalakshmi R, Rajesh N P and Ramasamy P, Cryst Res Technol., 2006, 41, 678.

11. Robert R, Justin Raj C and Jerome Das S, Current Appl Phys., 2010, 10, 670.

12. Rajendran K V, Jayaraman D, Jayavel R, Mohan Kumar R and Ramasamy P, J Cryst Growth., 2001, 224, 122. 


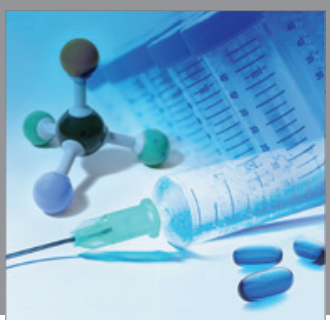

International Journal of

Medicinal Chemistry

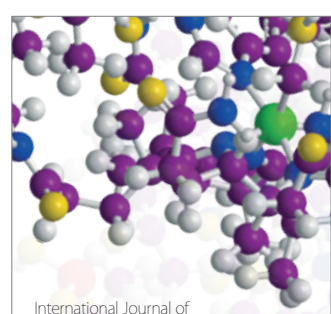

Carbohydrate Chemistry

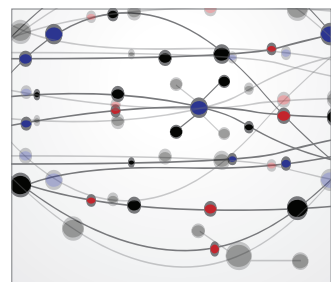

The Scientific World Journal
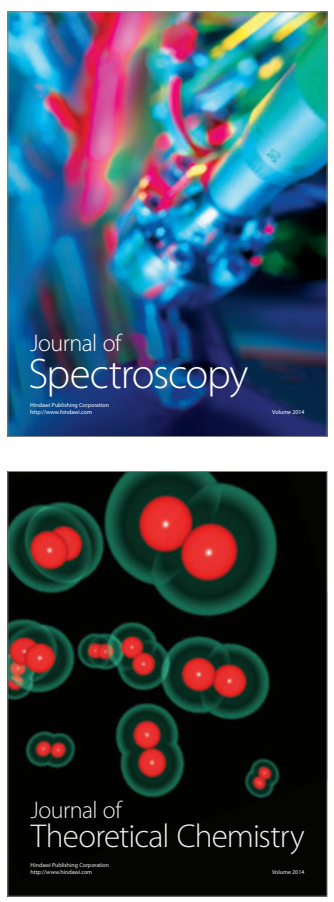
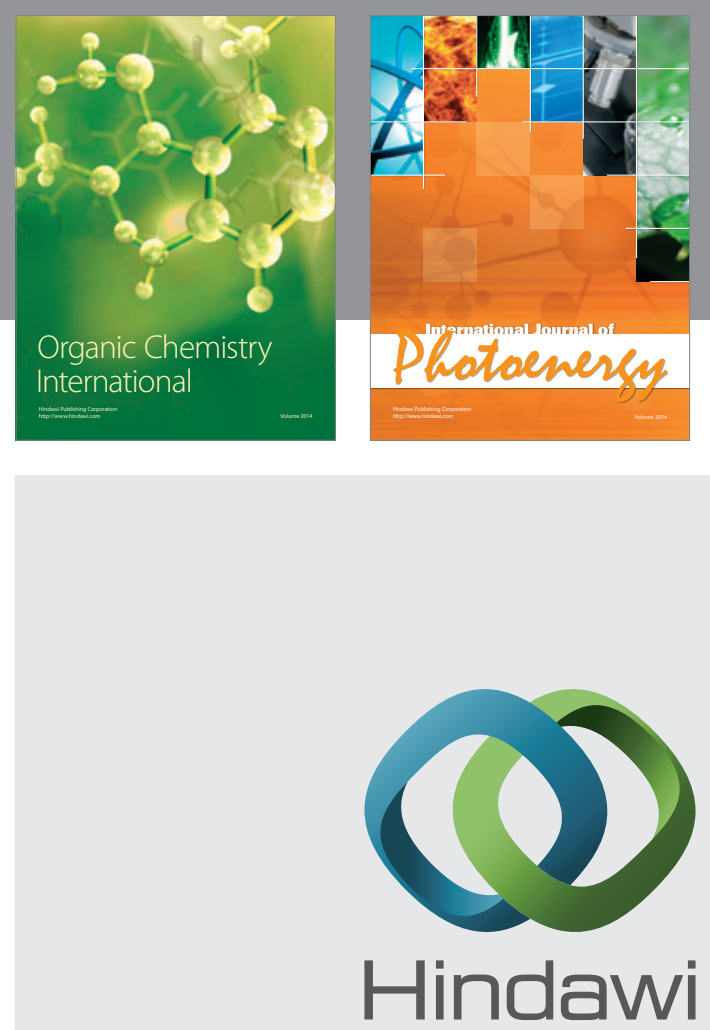

Submit your manuscripts at

http://www.hindawi.com
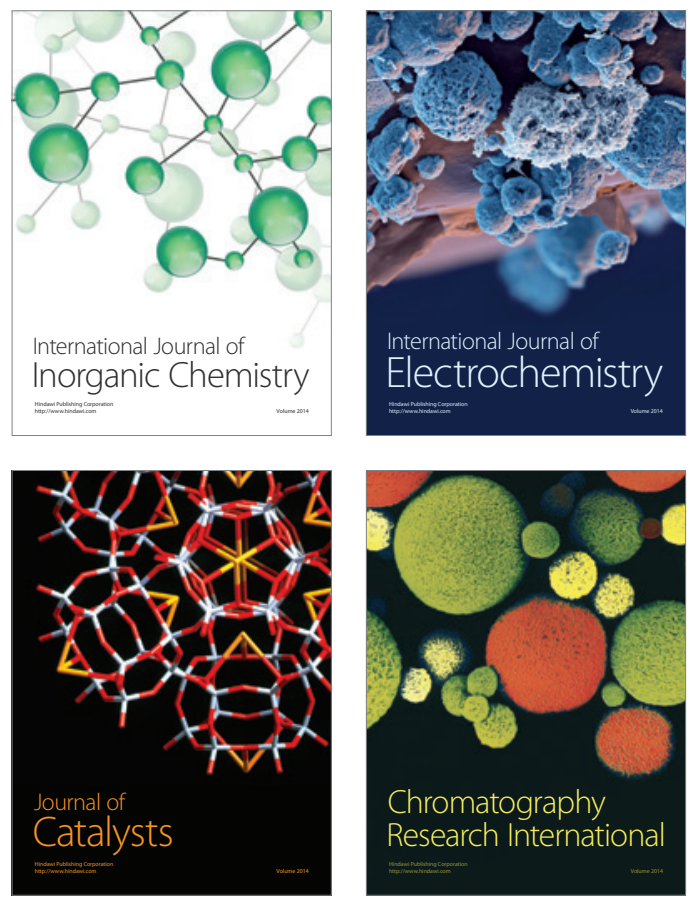
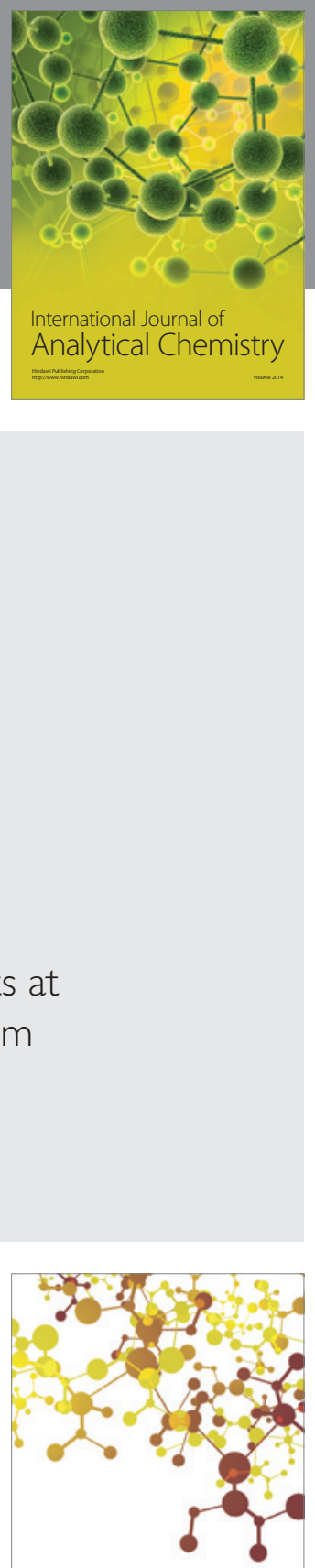

Journal of

Applied Chemistry
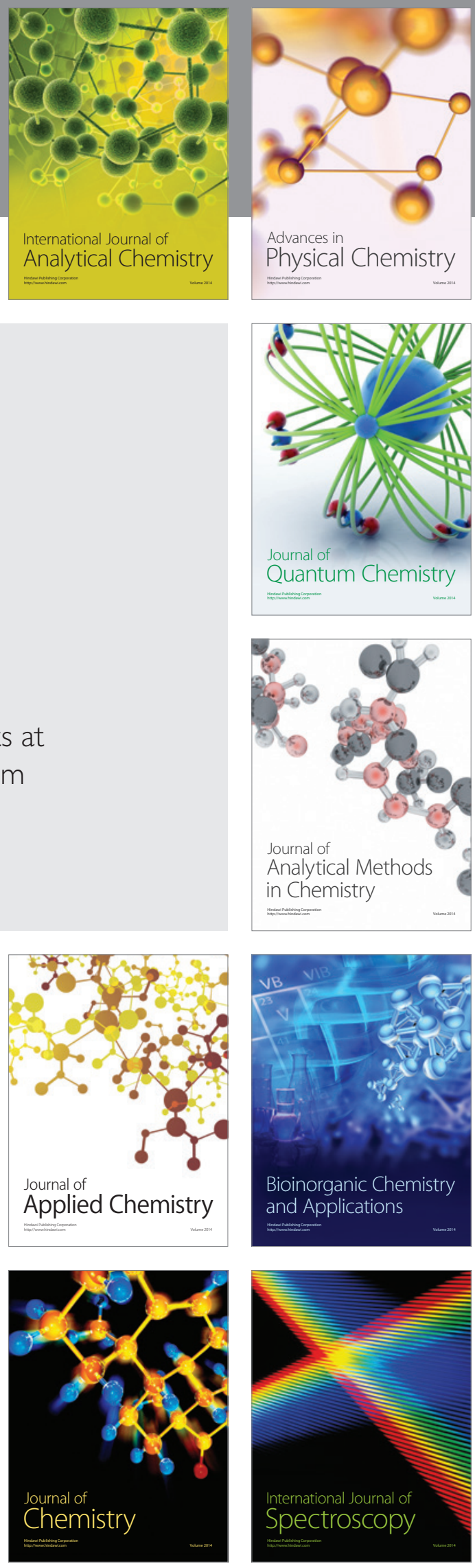